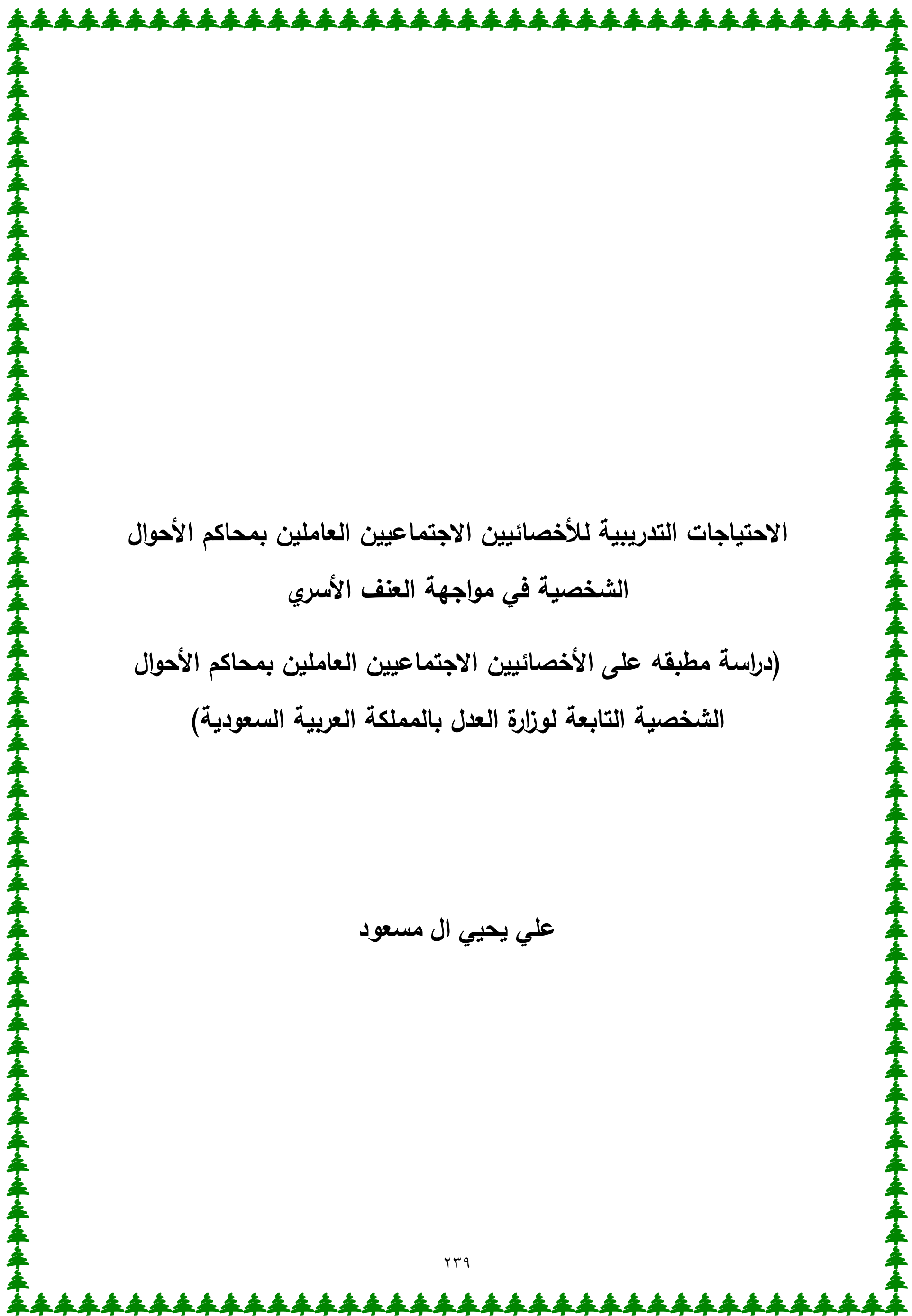




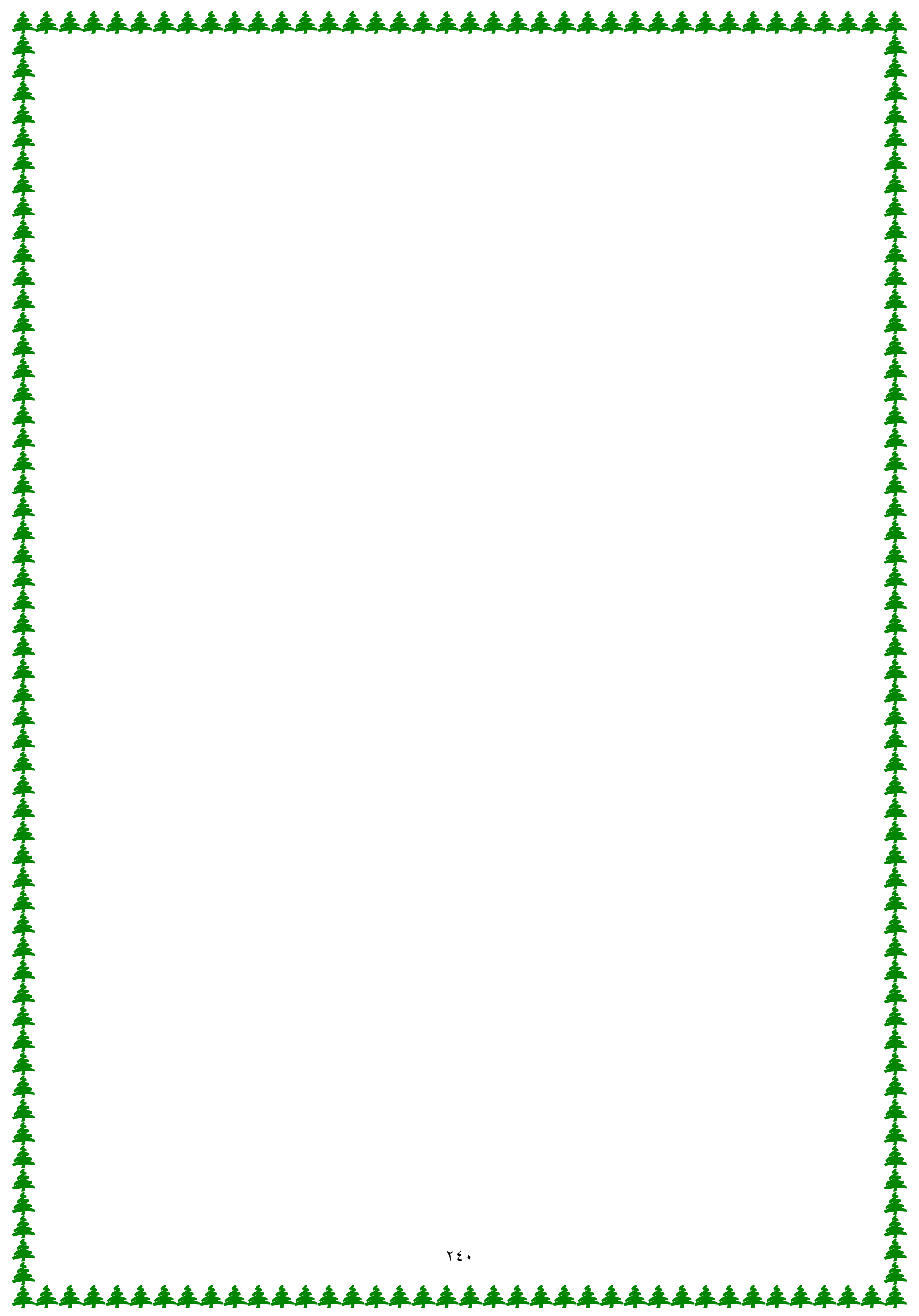




\section{Extract study}

THE study examines all the training needs of social workers employed courts of personal status in the face of domestic violence , and it has several objectives and questions about what are the needs of skill that must be mastered by the social worker in dealing with the phenomenon of domestic violence courts, personal status and what is the knowledge that must be mastered by specialist social in dealing with the phenomenon of domestic violence courts, personal status and what are the trends of social workers working in the personal status courts dealing with abused a family and try to reach the proposed training program to improve the performance of specialists in dealing with cases of domestic violence in the courts.

The study found several findings and recommendations of the most important that specialists see the importance of training on a number of professional skill which reported the results of the study as well as to identify the knowledge concerning the phenomenon of domestic violence and there is a need to develop their performance with regard to social theories and entrances therapeutic and was acceptance to work with domestic violence cases in personal status courts desire and willingness of them according to the results of the study.

And concluded the researcher a number of recommendations from the most important to intensify training courses in the field of skills and knowledge for social workers and open the way for graduate students to participate in this training and the use of modern technology and contemporary technology in support of training courses for social workers in the personal status courts 


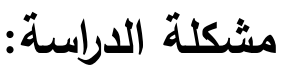

من القضايا المستحدثة التي بدأت نطفو على السطح وتتاقش في جميع القنوات قضية العنف الأسري حيث يشكل خطورة على الفرد والمجتمع والأسرة كما ذكر التقرير الأول لجمعية الدفاع عن حقوق المرأة السعودية إن (TVY) حالة عنف اسري أنهتها لجنة الحماية الاجتماعية بمدينة الطائف عام (9 . . rم)، أما بالنسبة للدراسات النوعية وهي الأكثر انتتارا فلم تتطرق إلى الحجم الإجمالي للظاهرة في هذه الدولة أو تلك ،إنما أولت اهتمامها بظروف العنف الأسرب، وخصائص الفاعلين، والضحايا وغير ذلك من الاعتبارات، ومن ذلك دراسة( أبو عسكر، r. rrم) التي شملت،(ع \&)، امرأة في تونس، وكذلك الحال في دراسة (اليوسف ،0 . . rم)، في المملكة العربية السعودية.

إن مشكلة العنف الأسري تتطلب بالضرورة تدخل مهني متخصص يمارس عمله بطريقه مهنيه، وإيمانا بأهمية الأسرة والحرص على تماسكها فعلت المملكة العربية السعودية محاكم تعنى بقضايا الأسرة من عنف ونفقه وغيرها من القضايا وذلك بعد توجيه خادم الحرمين الثريفين الملك

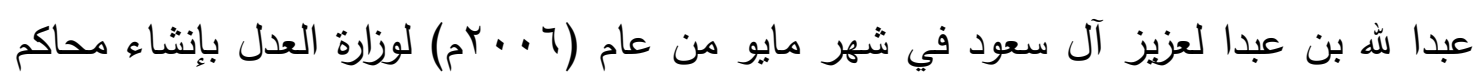
تعنى بمشاكل الأسرة ،وذلك بعد ازدياد المشاكل الأسرية التي أدت بدورها ازدياد عدد القضايا المرفوعة أمام المحاكم الثرعية في المملكة العببة السعودية.(الجوهزة آل

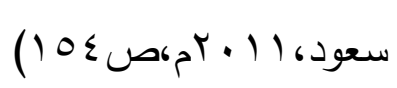

ومن هنا أراد الباحث في ضوء ازدياد ظاهرة العنف الأسري والحاجة إلى نمط معين من الأداء المهني يقوم بـهـ الأخصـائيون الاجتمـاعيون داخل المحـاكم العامـة ومحساكم الأحوال الثخصبية الوصول إلى أهم المهارات والمعارف التي يحتاج إليها الأخصائيين الاجتماعيين العاملين بمحاكم الأحوال الثخصية وكذلك التعرف على اتجاهاتهم نحو العمل بتلك المحاكم. وبنـاء على مـا تقدم بمكن تحديد مشـلة الدراسـة في "الاحتباجـات التدريبيـة للأخصـائيين الاجتماعيين العاملين بمحاكم الأحوال الثخصية في مواجهة ظاهرة العنف الأسري". 
الاجتماعيين العاملين بمحاكم الأحوال الثخصية بوزارة العدل بالمملكة العربية السعودية

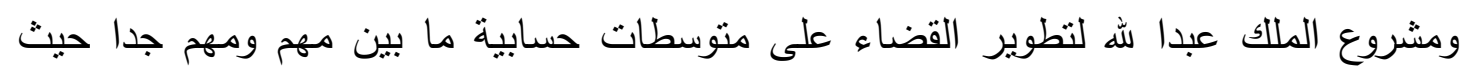

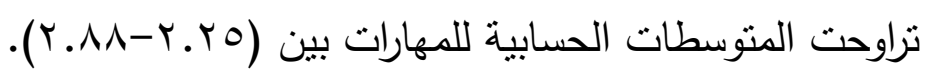

المحور الرابع: اتجاهات الأخصائيين الاجتماعيين نحو العمل بمحاكم الأحوال الشخصية في

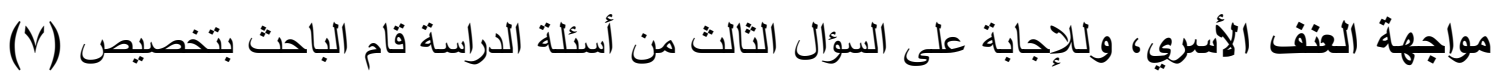

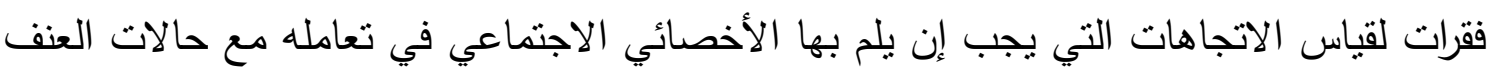
الأسري، وفيما يلي عرض نتائج إجابات أفراد العينة: جدول رقم(؟) المتوسطات الحسابية والانحرافات المعيارية والترتيب لفقرات اتجاهات الأخصائيين الاجتماعين في تعاملهم مع حالات العنف الأسري مرتبة تتازليا حسب المتوسطات وات الحسابية

\begin{tabular}{|c|c|c|c|c|c|}
\hline | - مرجة & 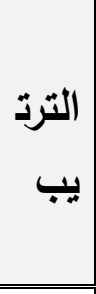 & $\begin{array}{r}\text { فالانحرا } \\
\text { المعيار } \\
\end{array}$ & سط الحسا & الفقرة & r \\
\hline 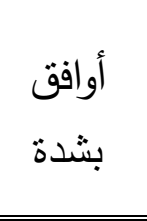 & 1 & . ro & r.qr & 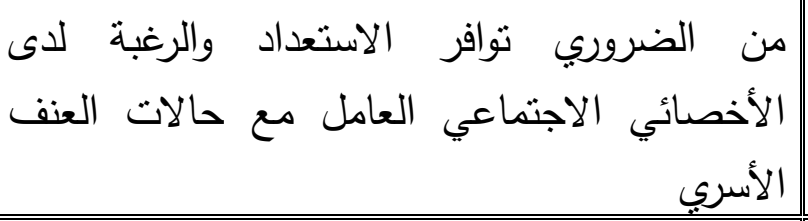 & 1 \\
\hline 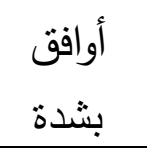 & r & 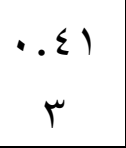 & Y.AT & من أدائي & 7 \\
\hline 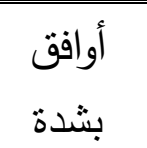 & r & . ro & r.AT & الأسري من أهم مجالأل الأخصائ الاجتماعي مع حالات العنف & V \\
\hline 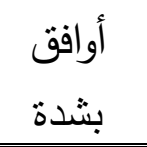 & $\varepsilon$ & 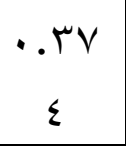 & Y.A & يعد العمل مع الحالات المعنفة اسريا رسالة إنسانية & r \\
\hline 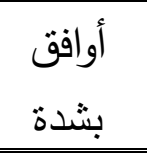 & 0 & $\begin{array}{c}.00 \\
1\end{array}$ & Y.01 & أكون سعيدا أثناء عملي مع حالات العنف الأسري & r \\
\hline 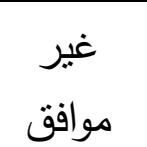 & 7 & . Tr & 1.14 & الأحوال الثخل مع حالات العنف الأسري ليست في محاكم & 0 \\
\hline 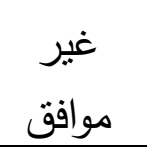 & V & 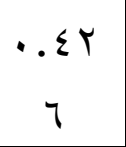 & $1 . .9$ & 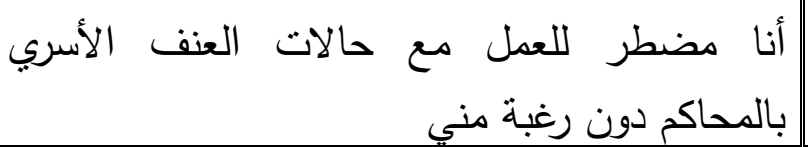 & $\varepsilon$ \\
\hline
\end{tabular}

يتبين من الجدول السابق (ع r ) أن فقرات محور اتجاهات الأخصائي الاجتماعي في تعامله مع حالات العنف الأسري حصلت على متوسطات حسابية تقع ما بين درجة غير موافق و أوافق

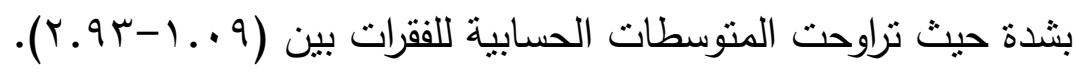


